\title{
Makedonya meşesi (Quercus trojana P.B. Webb.) fidanlarında kuraklık stresinin su potansiyeli ve gaz değişim parametreleri üzerindeki etkisi
}

\author{
Ayşe Deligöz ${ }^{a}$ (D), Esra Bayar ${ }^{a, *}$ (i)
}

\begin{abstract}
Özet: Küresel iklim değişikliğine bağlı olarak yaz kuraklıklarının süre uzunluğunun ve şiddetinin artması ormanları olumsuz etkileyecek olup, artan kuraklık nedeniyle ağaçların maruz kaldığı kuraklık stresinin tür bazında incelenmesi, türün verdiği tepkinin anlaşılması oldukça önemlidir. Bu çalışmada Quercus trojana P.B. Webb. fidanlarında kuraklık stresinin fizyolojik (gün ortası su potansiyeli, relatif su içeriği, gaz değişim parametreleri) ve biyokimyasal (toplam çözünebilir şeker içeriği) özellikler üzerindeki etkisi araştırılmıştır. Sera koşullarında 1+0 yaşlı fidanlara kontrol (haftada 2-3 kez sulama) ve kuraklık stresi (30 gün susuz bırakma) olmak üzere iki işlem uygulanmıştır. Kuraklık stresi ardışık iki kez tekrar edilmiştir. İki aylık stres döngüsü sonunda kuraklık stresi, gün ortası su potansiyelini, relatif su içeriğini, net fotosentez hızını, stoma iletkenliğini ve terleme oranını düşürürken, su kullanım etkinliğini ve toplam çözünebilir şeker içeriğini arttırmıştır. Çalışmada gün ortası su potansiyeli, net fotosentez hızı, stoma iletkenliği, terleme oranı ve toplam çözünebilir şeker içeriği arasında güçlü ilişkiler tespit edilmiştir.

Anahtar kelimeler: Su stresi, Quercus trojana, Gün ortası su potansiyeli, Fotosentez, Çözünebilir şeker
\end{abstract}

\section{Impact of drought stress on water potential and gas exchange parameters in Macedonian oak (Quercus trojana P.B. Webb.) seedlings}

\begin{abstract}
The increase in the duration and severity of summer droughts due to global climate change will adversely affect forests, and it is very important to examine the drought stress that trees are exposed to as a species due to increasing drought and to understand the response of the species. In this study, the effects of drought stress on physiological (midday water potential, relative water content, gas exchange parameters) and biochemical (total soluble sugar content) characteristics were investigated in Quercus trojana P.B. Webb. seedlings. Under greenhouse conditions, two treatments were applied to $1+0$ old seedlings: control (2-3 times a week for watering) and drought stress (no watering for 30 days). Drought stress was repeated twice, consecutively. At the end of the two-month stress cycle, drought stress decreased the midday water potential, relative water content, net photosynthesis rate, stomatal conductance and transpiration rate, while increasing the water use efficiency and total soluble sugar content. In the study, strong relationships were found between midday water potential, net photosynthesis rate, stomatal conductance, transpiration rate and total soluble sugar content.
\end{abstract}

Keywords: Water stress, Quercus trojana, Midday water potential, Photosynthesis, Soluble sugar

\section{Giriş}

Türkiye sahip olduğu topoğrafik yapısı ve iklim özelliğiyle, kuraklık ve çölleşme tehdidi ile karşı karşıya kalmakla birlikte (Türkeş, 2012), iklim değişikliğinden de önemli oranda etkilenecek ülkeler arasındadır (Türkeş, 2012; Tüfekçioğlu ve Tüfekçioğlu, 2018). İklim değişikliğinin sebep olduğu olaylardan biri de kuraklıktır. Kuraklığın artması, dünya çapında türlerin ve ekosistemlerin karşı karşıya olduğu en kritik zorluklardan biridir (Barlett vd., 2012). Bitki büyüme sürecinde ana kısıtlayıcı faktörlerden biri olan kuraklık, bitkilerin büyümesini, gelişimini (Farooq vd., 2009) ve fizyolojik metabolizmasını etkileyebilmektedir (Zhu, 2002; Yang vd., 2021). Fizyolojik parametrelerden biri olan yaprak su potansiyeli bir bitkinin doğrudan su durumunu göstermektedir. Gün ortası su potansiyeli, bitkinin hücre büyümesi veya fotosentez gibi fizyolojik faaliyetlerini sınırlayabilen bir değer olup, en düşük bitki su potansiyelini değerini yani azami su stresini ifade etmektedir (Genç ve
Yahyaoğlu, 2007) ve kuraklık stresiyle birlikte gün ortası su potansiyeli azalmaktadır (Deligöz ve Bayar, 2018). Bitkilerin hayatta kalması için en önemli biyolojik süreçlerden biri olarak kabul edilen fotosentez, kuraklık stresinden büyük ölçüde etkilenmektedir (Razi ve Muneer, 2021). Kuraklık stresi bitki yapraklarının relatif su içeriğini (RWC), su potansiyelini (Siddique vd., 2000), net fotosentez hızını (Zhang vd., 2015), terleme oranını ve stoma iletkenliğini azaltmakta, su kullanım etkinliğini arttırmaktadır (Galeano vd., 2019). Kuraklığın ilerlemesi aynı zamanda yapısal olmayan karbonhidrat dinamiklerini de etkileyebilmektedir (McDowell, 2011). Glikoz ve fruktoz gibi yapısal olmayan karbonhidrat grubundaki şekerler osmotik ayarlama ile birikebilmektedir (Turner, 2018).

Ülkemiz 22.93 milyon hektar orman alanına sahip olup, 6.75 milyon hektarı meşe türlerinden oluşmaktadır (OGM, 2020). Yapraklı ormanlar arasında yayılış alanı olarak en fazla meşe türleri yer almaktadır. Quercus trojana P.B. Webb. ülkemizde yayılış gösteren meşe türlerinden biri olup, $\begin{array}{lll}\text { a } & \text { Isparta Uygulamalı Bilimler Üniversitesi, Orman Fakültesi, Orman } \\ & \text { Mühendisliği Bölümü } \\ @ \quad * & \text { Corresponding author (İletişim yazarı): esrabayar@isparta.edu.tr } \\ \checkmark & \text { Received (Geliş tarihi): 29.09.2021, Accepted (Kabul tarihi): 02.12.2021 }\end{array}$
Citation (Atıf): Deligöz, A., Bayar, E., 2021. Makedonya meşesi (Quercus trojana P.B. Webb.) fidanlarında kuraklık stresinin su potansiyeli ve gaz değişim parametreleri üzerindeki etkisi. Turkish Journal of Forestry, 22(4): 366-370. DOI: $\underline{10.18182 / \text { tjf.1001789 }}$ 
$300 \mathrm{~m}$ rakımdan $1800 \mathrm{~m}$ rakıma kadar yetişebilmekte ve ortalama 10-12 m boy yapmaktadır. Soğuğa dayanıklı bir ağaç türüdür. Batı, Kuzeybatı ve Güneybatı Anadolu'da doğal yayılış alanı bulunmaktadır (Öztürk, 2013). Meşe türleri geniş bir coğrafi alana dağılmış olup (Epron vd., 1993), kurak dönemi tolere etme yetenekleri çevre koşullarına göre farklılık göstermektedir (Epron vd., 1993; Kuster vd., 2013). Küresel iklim değişikliğine bağlı olarak türün/türlerin vereceği tepkilerin anlaşılması, fizyolojik mekanizmaların anlaşılması ile bağlantılıdır. Bu çalışmada 1+0 yaşlı Quercus trojana fidanlarının kuraklık stresine verdiği tepki, kuraklık stresinin fizyolojik (gün ortası su potansiyeli, relatif su içeriği, net fotosentez hızı, stoma iletkenliği, terleme oranı ve su kullanım etkinliği) ve biyokimyasal (toplam çözünebilir şeker içeriği) parametreler üzerindeki etkisiyle değerlendirilmiştir.

\section{Materyal ve yöntem}

\subsection{Tohum temini ve deneme kuruluşu}

Araştırma materyali olarak Karaman orijinli $\left(36^{\circ} 40^{\prime} \mathrm{K}\right.$; $32^{\circ} 33^{\prime}$ D; Rakım: $\left.1450 \mathrm{~m}\right)$ Quercus trojana subsp. trojana (Makedonya meşesi) fidanları kullanılmıştır. 2018 yılı kasım ayında toplanan tohumlar, boş ve çürük tohum ayrımı yapıldıktan sonra ekim tarihine kadar polietilen torbalarda $+4^{\circ} \mathrm{C}$ 'de soğuk hava deposunda bekletilmiştir. 2019 yılı mart ayında yetiştirme ortamı olarak turba ve perlit karışımı (3:1) kullanılan 18x30 cm ebatlarındaki polietilen tüplere tohumlar ekilmiştir. Isparta Uygulamalı Bilimler Üniversitesi Orman Fakültesi Araştırma ve Uygulama Fidanlığında açık alan koşullarında yetiştirilen fidanlar 2020 yılı mayıs ayında cam sera içerisine taşınmıştır. Deneme başlayana kadar sera ortamında fidanlar düzenli aralıklarla sulanmıştır. Kuraklık stresi denemesi kontrol ve kuraklık olmak üzere temmuz ayında başlatılıp eylül ayında sonlandırılmıştır. Deneme süresince art arda iki kez kuraklık stresi uygulanan fidanlar, bir ay boyunca susuz birakılip bir ay sonunda tarla kapasitesinde sulanırken, kontrol fidanları deneme süresince haftada 2-3 kez sulanmıştır. Seranın sıcaklığı ve nemi data logger (Elitech RC-4HC) yardımıyla tespit edilmiştir. Buna göre deneme süresince ortalama sicaklık $23.5^{\circ} \mathrm{C}$ ile $28.0^{\circ} \mathrm{C}$ arasında değişirken, ortalama nem \% 32.0 ile \% 55.0 arasında değişmiştir.

\subsection{Fizyolojik ve biyokimyasal ölçümler}

Gün ortası su potansiyeli ölçümleri hem kontrol hem kuraklık işlemlerinde 4 fidandan alınan örneklerde Scholander vd. (1965) tarafindan geliştirilen bitki basınç odas1 cihazı (Model 600; PMS Instruments, Corvallis, Oregon) yardımıyla saat 12:00-13:00 arasında gerçekleştirilmiştir. Yaprağın relatif su içeriği (RWC), taze ağırlık (FW), turgor ağırlık (TW) ve kuru ağırlık (DW) temel alınarak hesaplanmıştır. Relatif su içeriğinin (RWC) belirlenmesinde, yaprak örnekleri hemen tartılıp (FW), karanlık ortamda yaklaşık 24 saat doygun hale getirilerek yeniden tartılmış (TW) ve ardından 24 sa $105 \mathrm{C}^{\circ}$ de firın kurusu ağırlığı (DW) belirlenmiştir. RWC aşağıdaki formül yardımıyla hesaplanmıştır:

$\mathrm{RWC}(\%)=100[(\mathrm{FW}-\mathrm{DW}) /(\mathrm{TW}-\mathrm{DW})]$
Gaz değişim parametreleri kontrol ve kuraklık işlemlerinde 4'er fidanın olgun yapraklarında LI-6400XT (Lincoln, USA) model taşınabilir fotosentez cihazı ile saat 09:00-11:00 arasında ölçülmüştür. Cihazın kalibrasyonu yapıldıktan sonra, fotosentetik aktif radyasyonu (PAR) 1250 $\mu \mathrm{mol} \mathrm{m}{ }^{-2} \mathrm{~s}^{-1}, \mathrm{CO}_{2}$ miktarı $400 \mathrm{ppm}$, akış oranı $500 \mu \mathrm{mol} \mathrm{s}^{-1}$ olarak ayarlanmıştır. Yaprak sıcaklığı, ölçüm sırasında seranın sıcaklığına bağlı olarak ayarlanmıştır. Tüm ölçümler dört tekerrürlü olarak kaydedilmiştir. Daha sonra ölçüm yapılan yapraklar kesilerek, Image J yazılım programı (NIH, Bethesda, MD, USA) yardımıyla yaprak alanı hesaplanmıştır. Net fotosentez hizl $\left(\mathrm{A}_{\text {net }}\right)\left(\mu \mathrm{mol} \mathrm{CO}_{2} \mathrm{~m}^{-2} \mathrm{~s}^{-1}\right)$, stoma iletkenliği (gs) $\left(\mathrm{mmol} \mathrm{H}_{2} \mathrm{O} \mathrm{m} \mathrm{m}^{-2} \mathrm{~s}^{-1}\right)$ ve terleme oranı (E) $\left(\mathrm{mmol} \mathrm{H} \mathrm{H}_{2} \mathrm{O} \mathrm{m}^{-2} \mathrm{~s}^{-1}\right.$ ) belirlenmiș ve su kullanım etkinliği (WUEi) ( $\left.\begin{array}{lllllllllll}\mu \mathrm{mol} & \mathrm{CO}_{2} & \mathrm{~m}^{-2} & \mathrm{~s}^{-1} / & \mathrm{mmol} & \mathrm{H}_{2} \mathrm{O} & \mathrm{m}^{-2} & \mathrm{~s}^{-1}\end{array}\right)$ hesaplanmıştır. Toplam karbonhidrat içeriği için yaprak örnekleri $65^{\circ}$ C'de 48 sa kurutularak Dubois vd. (1956) tarafından belirlenen fenol sülfürik asit yöntemine göre analiz edilmiştir.

\subsection{Istatistiksel analizler}

Fidanlarda belirlenen fizyolojik ve biyokimyasal özeliklere ait ortalama değerler SPSS 25.0 Windows paket programı yardımıyla belirlenmiştir. Her iki kuraklık döngüsü için kontrol ve kuraklık işlemleri arasında relatif su içeriği, gün ortası su potansiyeli, gaz değişim parametreleri ve toplam çözünebilir şeker içeriği bakımından farklılık olup olmadığını tespit etmek için Student's t testi uygulanmıştır. Yüzde olan değerlerde analiz öncesi arcsin dönüşümü yapılmıştır. Özellikler arasındaki ilişki korelasyon analizi ile tespit edilmiştir.

\section{Bulgular}

Birinci ve ikinci kuraklık döngüsü sonunda, kuraklık stresi uygulanan fidanlarda kontrol fidanlarına kıyasla gün ortası su potansiyeli önemli ölçüde azalmıştır. Kuraklık stresli fidanlarda birinci ve ikinci kuraklık döngüsünde sırasıyla gün ortası su potansiyeli $-3.43 \mathrm{MPa}$ ve $-3.60 \mathrm{MPa}$ olarak ölçülmüştür (Şekil 1a). İşlemler arasında birinci kuraklık döngüsünde relatif su içeriği bakımından fark çıkmazken, ikinci kuraklık döngüsünde kuraklık stresi uygulanan fidanlarda relatif su içeriği önemli ölçüde azalmıştır (Şekil 1b).

Kuraklık stresi uygulanan fidanlarda net fotosentez hızı, stoma iletkenliği ve terleme oranı daha düşüktür. Su kullanım etkinliği ikinci kuraklık döngüsü sonunda, kuraklık stresi uygulanan fidanlarda daha yüksek çıkmıştır (Çizelge 1).

Birinci ve ikinci kuraklık döngüsü sonunda işlemler arasında toplam çözünebilir şeker içeriğinde 0.05 önem düzeyinde anlamlı farklılık çıkmıştır. Kuraklık stresi uygulanan fidanlar daha yüksek toplam çözünebilir içeriğine sahiptir (Şekil 2).

Özellikler arasındaki ilişkiler incelendiğinde, gün ortası su potansiyeli ile net fotosentez hızı, stoma iletkenliği ve terleme oranı ile güçlü ve pozitif ilişki tespit edilirken, toplam çözünebilir şeker içeriği arasında güçlü ve negatif bir ilişki belirlenmiştir (Çizelge 2). Gün ortası su potansiyelinin azalması ile net fotosentez hızı, stoma iletkenliği ve terleme oranı azalmakta, toplam çözünebilir şeker içeriği artmaktadır. 


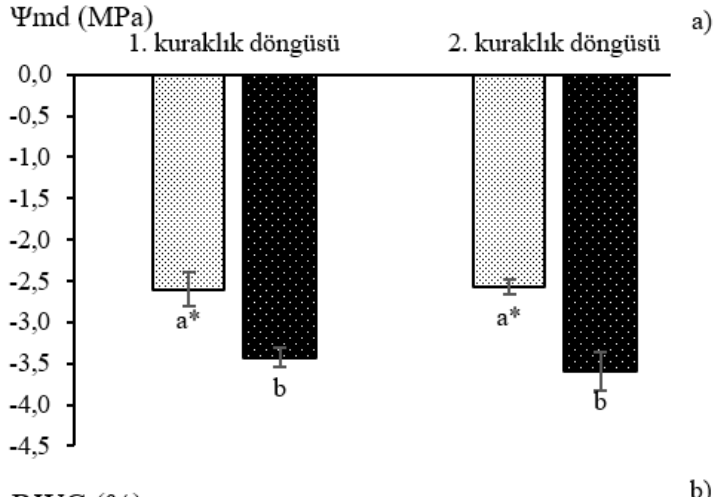

RWC (\%)

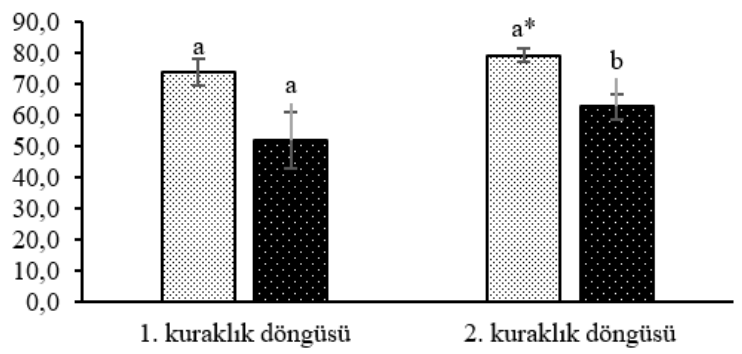

@Kontrol aKuraklık ortalama \pm ortalamanın standart hatası $(n=4)$ şeklinde verilmiştir. *İşlemler arasında 0.05 önem düzeyinde anlamlı fark vardır)

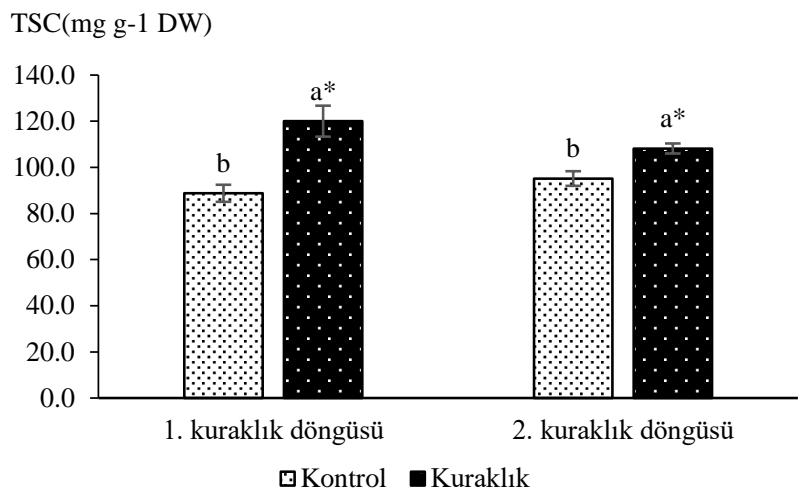

Şekil 2. Kuraklık stresinin toplam çözünebilir şeker içeriği (TSC) üzerindeki etkisi (Sütunlar ortalama \pm ortalamanın standart hatası şeklinde verilmiştir. *İşlemler arasında 0.05 önem düzeyinde anlamlı fark vardır)

Şekil 1. Kuraklık stresinin a) gün ortası su potansiyeli ( $\left.\Psi_{\mathrm{md}}\right)$ ve b) relatif su içeriği (RWC) üzerindeki etkisi (Sütunlar

Çizelge 1. Kuraklık stresinin $\mathrm{A}_{\text {net }}$ (net fotosentez hızı), gs (stoma iletkenliği), E (terleme oranı) ve WUEi (su kullanım etkinliği) üzerindeki etkisi

\begin{tabular}{|c|c|c|c|c|c|}
\hline & İşlemler & $\mathrm{A}_{\text {net }}\left(\mu \mathrm{molCO}_{2} \mathrm{~m}^{-2} \mathrm{~s}^{-1}\right)$ & $\begin{array}{c}\mathrm{gs} \\
\left(\mathrm{mmol} \mathrm{H} \mathrm{O} \mathrm{m}^{-2} \mathrm{~s}^{-1}\right)\end{array}$ & $\begin{array}{c}\mathrm{E} \\
\left(\mathrm{mmol} \mathrm{H} \mathrm{O} \mathrm{m}^{-2} \mathrm{~s}^{-1}\right)\end{array}$ & $\begin{array}{c}\text { WUEi }\left(\mu \mathrm{molCO}_{2} \mathrm{~m}^{-2} \mathrm{~s}^{-1} / \mathrm{mmol}\right. \\
\left.\mathrm{H}_{2} \mathrm{O} \mathrm{m}^{-2} \mathrm{~s}^{-1}\right)\end{array}$ \\
\hline \multirow{3}{*}{$\begin{array}{l}\text { 1. kuraklık } \\
\text { döngüsü }\end{array}$} & Kontrol & $11.53 \pm 0.44 \mathrm{a}$ & $296.13 \pm 18.03 a$ & $10.64 \pm 0.54 \mathrm{a}$ & $1.12 \pm 0.07$ \\
\hline & Kuraklık & $3.10 \pm 0.53 b$ & $48.86 \pm 7.83 b$ & $2.14 \pm 0.32 b$ & $1.51 \pm 0.22$ \\
\hline & Önem Düzeyi & $* *$ & $* *$ & $* *$ & ns \\
\hline \multirow{3}{*}{$\begin{array}{l}\text { 2. kuraklık } \\
\text { döngüsü }\end{array}$} & Kontrol & $12.49 \pm 1.08 \mathrm{a}$ & $258.22 \pm 32.23 a$ & $8.97 \pm 0.97 a$ & $1.53 \pm 0.10$ \\
\hline & Kuraklık & $5.13 \pm 0.60 b$ & $58.31 \pm 6.36 \mathrm{~b}$ & $2.50 \pm 0.27 \mathrm{~b}$ & $1.97 \pm 0.11$ \\
\hline & Önem Düzeyi & $* *$ & $* *$ & $* *$ & $*$ \\
\hline
\end{tabular}

**işslemler arasında 0.01 önem düzeyinde anlamlı fark vardır. * İşlemler arasında 0.05 önem düzeyinde anlamlı fark vardır. ns: İşlemler arasında 0.05 önem düzeyinde anlamlı fark yoktur.

Çizelge 2. Bazı özelliklere ilişkin korelasyon analizi sonuçları

\begin{tabular}{lccccc}
\hline & $\Psi_{\mathrm{md}}$ & $\mathrm{A}$ & $\mathrm{Gs}$ & $\mathrm{E}$ & $\mathrm{TSC}$ \\
\hline$\Psi_{\mathrm{md}}(\mathrm{MPa})$ & 1 & & & & \\
$\mathrm{~A}_{\text {net }}\left(\mu \mathrm{molCO} \mathrm{m}^{-2} \mathrm{~s}^{-1}\right)$ & $.855^{* *}$ & 1 & & & \\
$\mathrm{gs}\left(\mathrm{mmol} \mathrm{H}_{2} \mathrm{O} \mathrm{m}^{-2} \mathrm{~s}^{-1}\right)$ & $.853^{* *}$ & $.905^{* *}$ & 1 & & \\
$\mathrm{E}\left(\mathrm{mmol} \mathrm{H}_{2} \mathrm{O} \mathrm{m} \mathrm{s}^{-1}\right)$ & $.852^{* *}$ & $.908^{* *}$ & $.996^{* *}$ & 1 & \\
$\mathrm{TSC}\left(\mathrm{mg} \mathrm{g}^{-1} \mathrm{DW}\right)$ & $-.791^{* *}$ & $-.697^{*}$ & $-.864 * *$ & $-.865^{* *}$ & 1 \\
\hline
\end{tabular}

$\Psi_{\text {md: }}$ Gün ortası su potansiyeli, $\mathrm{A}_{\text {net }}$ : Net fotosentez hızı, gs: Stoma iletkenliği, E: Terleme oranı, TSC: Toplam çözünebilir şeker içeriği, *Korelasyon p= 0.05 seviyesinde anlaml, ${ }^{* *}$ Korelasyon $\mathrm{p}=0.01$ seviyesinde anlaml

\section{Tartışma ve sonuç}

Kuraklık stresi fizyolojik ve biyokimyasal parametreler üzerinde etkili olmuştur. Özellikle Quercus trojana fidanlarının su potansiyelini değiştirmiştir. Quercus trojana fidanları ikinci kuraklık döngüsü sonunda gün ortası su potansiyelini -3.6 MPa'ya düşürmüştür. Benzer şekilde Quercus brantii Lindl. fidanlarında da şiddetli kuraklık stresi ksilem su potansiyelini düşürmüștür (Jafarnia vd., 2018). Bitkiler su potansiyelini mümkün olduğunca yüksek tutarak veya düşük su potansiyelini tolere ederek kurak koşullara dayanabilirler (Chaves vd., 2003). Kurak dönemde yapılan başka bir çalışmada gün ortası su potansiyeli $Q$. frainetto Ten. için -5.9 MPa, Q. macrolepis Kotschy için -6.0 MPa, Q. ilex L. için -4.8 MPa ve $Q$. pubescens Willd.'de -5.0 MPa olarak tespit edilmiştir. Kuraklık stresi, su potansiyeli ve relatif su içeriğini azaltmaktadır (Fotelli vd., 2000). RWC bitki su durumunu gösteren uygun bir gösterge olabilir (Chaves, 1991). İkinci kuraklık döngüsü sonunda kuraklık stresli fidanlarda RWC azalmıştır. Relatif su içeriğindeki değişimler 
kökler tarafından su alımı ve yapraklardan terleme yoluyla su kayb1 ile ilişkilidir (Anjum vd., 2011). Gün ortası su potansiyeli ile fotosentez hızı, stoma iletkenliği ve terleme oranı arasında pozitif yönde güçlü bir ilişki bulunmaktadır. Kuraklık stresi sonunda gün ortası su potansiyelinin azalmasıyla net fotosentez hızı, stoma iletkenliği ve terleme oranı da azalmıştır. Bitkiler su kaybını en aza indirgemek için stomalarını hızlı bir şekilde daraltır veya kapatırlar. Dolayısıyla $\mathrm{CO}_{2}$ alımı azaldığı için fotosentez hızı doğrudan etkilenmektedir (Chaves vd., 2009). Kuraklık stresi, bitkilerin fizyolojisinin birçok yönünü, özellikle fotosentez kapasitesini olumsuz etkilemektedir (Osakabe vd., 2014). Birçok çalışmada kuraklık stresi altında gaz değişim parametrelerinin azaldığ Peguero-Pina vd., 2009). Su kullanım etkinliği (WUE), kuraklığa dayanıklılığın değerlendirilmesi için önemli bir göstergedir (Yin vd., 2005). Kuraklık stresi uygulanan fidanlarda su kullanım etkinliği yüksek çıkmıştır. Yapılan çalışmalarda da kuraklık stresinin, su kullanım etkinliğini önemli ölçüde arttırdığı bildirilmiştir (Zhang vd., 2004; Yin vd., 2006). Kuraklık koşullarında bitkiler stoma kapanması yoluyla terlemeyle su kaybını en aza indirerek net $\mathrm{CO}_{2}$ alımını azaltır, ancak bitkinin düşük su potansiyelinden kaçınmasına izin verirken anlık su kullanım etkinliğini arttırabilmektedir (Williams vd. 1999). Benzer şekilde Taiz ve Zeiger (2002), kuraklık stresinin erken evrelerinde stomaların kapanmasının terlemeyi engellediğini ve su kullanım etkinliğinin arttırabildiğini ifade etmiştir. Su kullanım etkinliğinin artması iyi adapte olmuş genotiplerde gözlenmektedir (Chaves, 1991).

Kuraklık toleransını arttırmanın bir yolu, ozmolit olarak bilinen aktif çözünen maddelerin birikmesidir (Yin vd., 2005). Toplam çözünebilir şeker içeriği ozmolit olarak bilinen maddelerden biri olup, kuraklık stresi sonucunda artmıştır. İki kuraklık döngüsünde de kontrol fidanlarına kıyasla, kuraklık stresi uygulanan fidanlarda toplam çözünebilir şeker içeriği yüksektir. Benzer sonucu Holland vd. (2016) Quercus pubescens Willd.'de, Wu vd. (2013) Quercus variabilis Bl.'de bulmuştur. Çözünebilir karbonhidratların ozmotik çözünenler olarak hareket edebileceği ve su stresi altındaki bitkilerde ozmoregülasyona katkıda bulunabileceği iyi bilinmektedir (Epron ve Dreyer, 1996). Yani kuraklık stresi altında bitkinin su stresi oranına büyük ölçüde bağlı olan bu tür çözünen maddelerin birikim süreci, osmotik ayarlama olarak bilinmektedir (Anjum vd., 2011).

Sonuç olarak, kuraklık stresine maruz kalan Quercus trojana fidanlarının fizyolojik ve biyokimyasal özelliklerinde birtakım değişiklikler meydana gelmiştir. Gün ortası su potansiyeli ile net fotosentez hızı, stoma iletkenliği, terleme oranı ve toplam çözünebilir şeker içeriği arasında güçlü ilişkiler tespit edilmiştir. Kuraklık stresi altında gün ortası su potansiyelini düşüren fidanlar, fotosentez hızı, stoma iletkenliği ve terleme oranını azaltırken, su kullanım etkinliğini arttırmıştır. Quercus trojana fidanları kuraklık stresi karşısında toplam çözünebilir şeker birikimiyle strese uyum gücünü yükseltmiştir. Meşe cenneti olan ülkemizde meşe türlerinin kuraklık stresi karşısındaki tepkisinin anlaşılması ve küresel iklim değişikliğiyle birlikte değişen çevre koşullarına karşı kuraklığı tolere edebilecek türlerinin belirlenmesi, gelecekteki ağaçlandırma çalışmalarına yön verilebilmesi açısından oldukça önemlidir.

\section{Kaynaklar}

Allam, S.M., 1999. Nutrient uptake by plants under stress conditions, In: Handbook of plant and crop stress (Ed:Pessarakli, M.), Marcel Dekker, New York. pp. 285-313.

Anjum, S.A., Xie, X., Wang, L., Saleem, M.F., Man, C., Lei, W., 2011. Morphological, physiological and biochemical responses of plants to drought stress. African Journal of Agricultural Research, 6(9):2026-2032.

Barlett, M.K., Scoffoni, C., Sack, L., 2012. The determinants of leaf turgor loss point and prediction of drought tolerance of species and biomes: a global meta-analysis. Ecology Letters, 15:393405.

Chaves, M.M., 1991. Effects of water deficits on carbon assimilation. Journal of Experimental Botany, 42(234):1-16.

Chaves, M.M., Maroco, J.P., Pereira, J.S., 2003. Understanding plant responses to drought-from genes to the whole plant. Functional Plant Biology, 30:239-264.

Chaves, M.M., Flexas, J., Pinheiro, C., 2009. Photosynthesis under drought and salt stress: regulation mechanisms from whole plant to cell. Annals of Botany, 103:551-560.

Deligöz, A., Bayar, E., 2018. Drought stress responses of seedlings of two oak species (Quercus cerris and Quercus robur). Turkish Journal of Agriculture and Forestry, 42:114-123.

Dubois, M, Gilles, K.A., Hamilton, J.K., Rebers, P.A., Smith, F., 1956. Calorimetric method for determination of sugars and related substances. Analytical Chemistry, 28: 350-356.

Epron, D., Dreyer, E., Aussenac, G., 1993. A comparison of photosynthetic responses to water stress in seedlings from 3 oak species: Quercus petraea (Matt) Liebl, $Q$ rubra $\mathrm{L}$ and $Q$ cerris L. Ann Sci For., 50(1):48-60.

Epron, D., Dreyer, E., 1996. Starch and soluble carbohydrates in leaves of water-stressed oak saplings. Ann. Sci. For., 53: 263268.

Farooq, M., Wahid, A., Kobayashi, N., Fujita, D., Basra, S.M.A., 2009. Plant drought stress: effects, mechanisms and management. Agronomy for Sustainable Development, 29:185212.

Fotelli, M.N., Radoglou, K.M., Constantinidou, H.I.A., 2000. Water stress response of seedlings of four Mediterranean oak species. Tree Physiology, 20:1065-1075.

Galeano, E., Vasconcelos, T.S., Novais de Oliveira, P., Carrer, H., 2019. Physiological and molecular responses to drought stress in teak (Tectona grandis L.f.). Plos One, 14(9): e0221571.

Genç, M., Yahyaoğlu, Z., 2007. Kalite sinıflamasında kullanılan özellikler ve tespiti. Fidan Standardizasyonu, Standart Fidan Yetiştirmenin Biyolojik ve Teknik Esasları (Ed: Yahyaoğlu, Z., Genç, M.), Süleyman Demirel Üniversitesi Yayınları, Yayın No. 75, Isparta, s:467-491

Holland, V., Koller S., Lukas, S., Brüggemann W., 2016. Droughtand frost-induced accumulation of soluble carbohydrates during accelerated senescence in Quercus pubescens. Trees, 30:215226

Jafarnia, S., Akbarinia M., Hosseinpour, B., Modarres Sanavi S.A.M., Salami S.A., 2018. Effect of drought stress on some growth, morphological, physiological, and biochemical parameters of two different populations of Quercus brantii. iForest, 11: 212-220.

Kuster, T.M., Arend, M., Günthardt-Goerg, M.S., Schulin, R., 2013. Root growth of different oak provenances in two soils under drought stress and air warming conditions. Plant Soil, 369:6171.

McDowell, N.G., 2011. Mechanisms linking drought, hydraulics, carbon metabolism, and vegetation mortality. Plant Physiology, 155:1051-1059.

OGM, 2020. Ormanc1l1k İstatistikleri 2020. Orman Genel Müdürlüğ̈̈, Ankara, https://www.ogm.gov.tr/tr/ekutuphane/resmi-istatistikler. Erişim:01.09.2021

Osakabe, Y., Osakabe, K., Shinozaki, K., Tran, L.S., 2014. Response of plants to water stress. Frontiers in Plant Science. 5(86):1-8. 
Öztürk, S., 2013. Türkiye Meşeleri Teşhis ve Tanı Kılavuzu. Orman ve Su İşleri Bakanlığı, Orman Genel Müdürlüğü, Ankara.

Peguero-Pina, J.J., Sancho-Knapik, D., Morales F., Flexas, J., GilPelegrín E., 2009. Differential photosynthetic performance and photoprotection mechanisms of three Mediterranean evergreen oaks under severe drought stress. Functional Plant Biology, 36: 453-462.

Razi, K., Muneer, S., 2021. Drought stress-induced physiological mechanisms, signaling pathways and molecular response of chloroplasts in common vegetable crops. Critical Reviews in Biotechnology, 41(5):669-691.

Scholander, P.F., Hammel, H.T., Bradstreet, E.D., Hemmingsen, E.A., 1965. Sap pressure in vascular plants. Science, 148:339346.

Siddique, M.R.B., Hamid, A., Islam, M.S., 2000. Drought stress effects on water relations of wheat. Bot. Bull. Acad.Sin., 41:3539.

Taiz, L., Zeiger E., 2002. Plant Physiology, Third Edition. Sinauer Associates, Inc. Publishers, Sunderland, U.S.A.

Turner, N.C., 2018. Turgor maintenance by osmotic adjustments: 40 years of progress. Journal of Experimental Botany, 69 (13):3223-3233

Tüfekçioğlu, A., Tüfekçioğlu, M., 2018. Kuraklık ve orman ekosistem dinamikleri etkileşimi. Türkiye Ormancılık Dergisi, 19(1):103-108.

Türkeş, M., 2012. Türkiye'de gözlenen ve öngörülen iklim değişikliği, kuraklık ve çölleşme. Ankara Üniversitesi Çevre Bilimleri Dergisi, 4(2):1-32.
Williams, D.G., McPherson G.R., Weltzin, J.F., 1999. Stress in Wildland Plants:Implications for ecosystem structure and function. In: Handbook of Plant and Crop Stress (Ed:Pessarakli M.) Marcel Dekker, New York, pp.907-929.

Wu, M., Zhang, W.H., Ma, C., Zhou, J.Y., 2013.Changes in morphological, physiological, and biochemical responses to different levels of drought stress in Chinese cork oak (Quercus variabilis B1.) seedlings. Russian Journal of Plant Physiology, 60(5): 681-692.

Yang, X., Lu, M., Wang, Y., Wang, Y., Liu, Z., Chen, S., 2021. A review on response mechanism of plants to drought stress. Horticulturae, 7:50.

Yin, C., Peng, Y., Zang, R., Zhu, Y., Li, C., 2005. Adaptive responses of Populus kangdingensis to drought stress. Physiologia plantarum, 123:445-451.

Yin, C.Y., Berninger, F., Li, C.Y., 2006.Photosynthetic responses of Populus przewalski subjected to drought stress. Photosynthetica, 44(1):62-68.

Zhang, X., Zang, R., Li, C., 2004. Population differences in physiological and morphological adaptations of Populus davidiana seedlings in response to progressive drought stress. Plant Science, 166: 791-797.

Zhang, T., Cao, Y., Chen, Y., Liu G., 2015. Non-structural carbohydrate dynamics in Robinia pseudoacacia saplings under three levels of continious drought stress. Trees, 29:1837-1849.

Zhu, J.K., 2002. Salt and drought stress signal transduction in plants. Annu Rev Plant Biol., 53:247-273. 